\title{
Mammalian circannual pacemakers
}

\author{
GA Lincoln' and DG Hazlerigg ${ }^{2}$ \\ 'University of Edinburgh, Centre for Reproductive Biology, Queen's Medical Research Institute, \\ Edinburgh EH16 4T7; ${ }^{2}$ University of Aberdeen, School of Biological Sciences, Zoology Building, \\ Aberdeen AB24 $2 T Z$
}

\begin{abstract}
Circannual clocks drive rhythms in reproduction and many other seasonal characteristics but the underlying control of these long-term oscillators remains a mystery. Now, we propose that circannual timing involves mechanisms that are integral to the ontogenetic life-history programme where annual transitions are generated by cell birth, death and tissue regeneration throughout the life cycle - the histogenesis hypothesis. The intrinsic cycle is then timed by cues from the environment. The concept is that in specific sites in the brain, pituitary and peripheral tissues, residual populations of progenitor cells (adult stem cells) synchronously initiate a phase of cell division to begin a cycle. The progeny cells then proliferate, migrate and differentiate, providing the substrate that drives physiological change over long time-spans (e.g. summer/winter); cell death may be required to trigger the next cycle. We have begun to characterise such a tissue-based timer in our Soay sheep model focusing on the pars tuberalis (PT) of the pituitary gland and the sub-ventricular zone of the mediobasal hypothalamus $(\mathrm{MBH})$ as potential circannual pacemakers. The PT is of special interest because it is a melatonin-responsive tissue containing undifferentiated cells, strategically located at the gateway between the brain and pituitary gland. The PT also governs long-photoperiod activation of thyroid hormone dependant processes in the $\mathrm{MBH}$ required for neurogenesis. In sheep, exposure to long photoperiod markedly activates BrDU-labelled cell proliferation in the PT and $\mathrm{MBH}$, and acts to entrain the circannual reproductive cycle. Variation in expression and co-ordination of multiple tissue timers may explain species differences in circannual rhythmicity. This paper is dedicated to the memory of Ebo Gwinner ${ }^{3}$.
\end{abstract}

\section{Circannual rhythms and photoperiod time measurement}

Organisms utilise two interacting timing mechanisms to regulate long-term cycles in reproduction, hibernation, moult and a plethora of seasonal characteristics (Figure 1). The principle mechanism is circannual rhythm generation where the long-term transitions in physiology are controlled endogenously by some form of interval timer or pacemaker. Circannual rhythms have been characterised in many model species notably hibernating ground squirrels and hamsters (Pengelley \& Asmundson, 1974; Mrosovsky, 1978; Zucker, 2001; Concannon et al.,

\footnotetext{
Corresponding author E-mail: gerald.lincoln@ed.ac.uk
}

${ }^{3}$ This hypothesis was first presented for The Gwinner Lecture at the XI Congress of the European Biological Rhythms Society (EBRS) meeting in Strasbourg, France August 22-28, 2009. 
1997; Kondo et al., 2006; Monecke et al., 2009), seasonal breeding deer, sheep and mustellids (Ducker et al., 1973; Goss, 1977, 1984; Herbert et al., 1978; Karsch et al., 1989; Martinet et al., 1992; Gomez-Brunet et al., 2008), seasonal migratory birds (Gwinner, 1986, 1996; Piersma et al., 2008), spawning fish (Dunstan \& Bromage, 1988; Randall et al., 1998), and notably in an insect model, the varied carpet beetle Anthrenus, that uses a circannual clock to regulate winter diapause and hatching (Nisimura \& Numata, 2002; Miyazaki et al., 2005, 2007, 2009). Circannual rhythmicity is also a feature in primates including man (Wickings \& Nieschlag, 1980; Wehr, 2001). The intrinsic control is evident by the manner the various physiological rhythms free-run under constant experimental conditions. The endogenous period (circannual tau) is different from the Earth's 12-month year, often closer to 10 months, and synchrony is achieved by entrainment to periodic environmental cues.
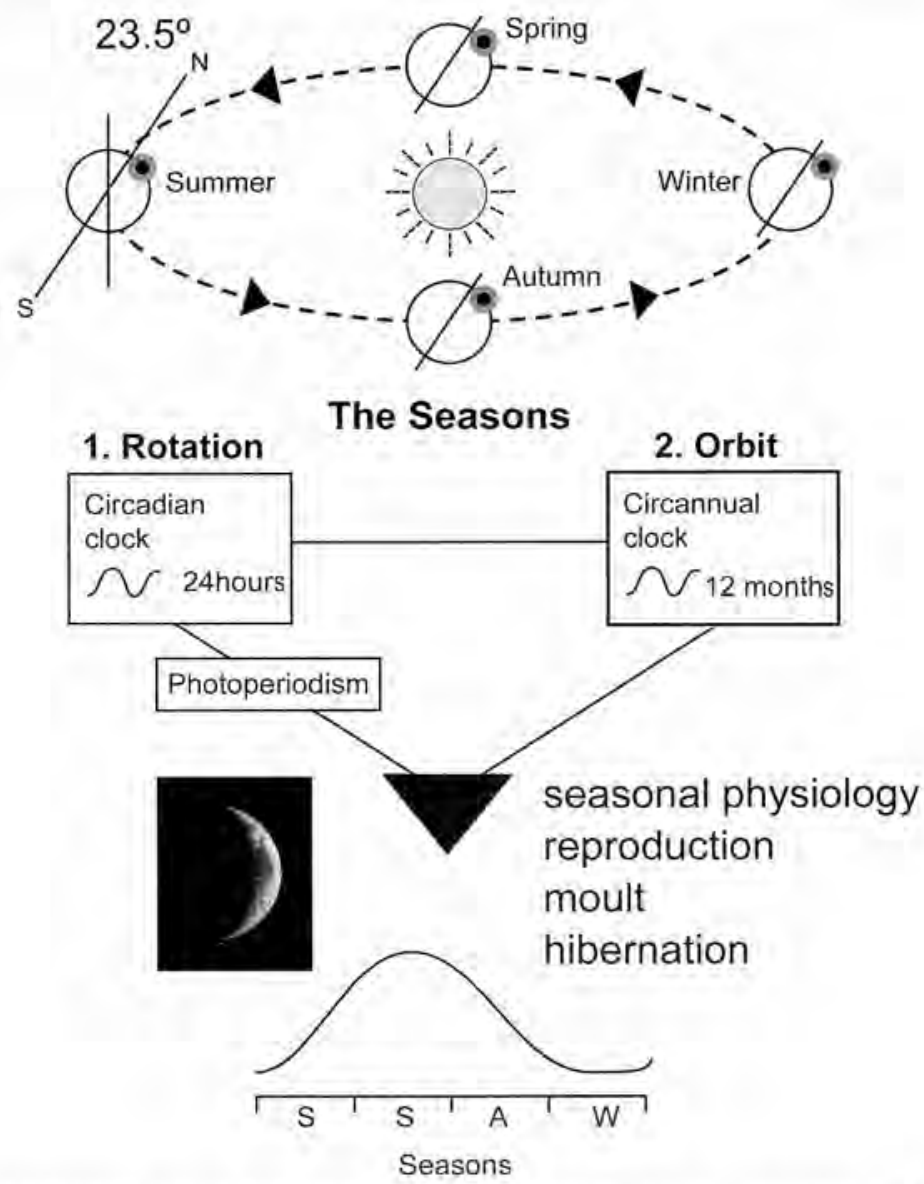

Fig. 1. Endogenous clocks anticipate the Earth's periodicities. Summary of the way the Earth's rotation on its axis every $24 \mathrm{~h}$ (top panel; line $\mathrm{S} / \mathrm{N}$ across earth indicates the rotational axis and the filled circle represents point of reference) and orbit around the Sun every 12 months have favoured the evolution of endogenous circadian clocks (based on circadian clock genes) and circannual clocks (based on tissue regeneration - current paper). The ability to respond to the annual cycle in daylength (photoperiod time measurement or photoperiodism) depends on the circadian clock system. Organisms utilise both timing mechanisms to regulate long-term cycles in reproduction, moult, hibernation and other seasonal characteristics. 
Circannual rhythmicity is of fundamental importance because it allows complex changes in physiology (e.g. growth of the gonads and secondary sexual characteristics, deposition of fat reserves, growth of the winter coat) to be complete in advance of environmental change as a pre-emptive strategy anticipating the effects of the Earth's orbit (Lincoln, 2006a; Figure 1). It also allows organisms to migrate across time zones while maintaining an intrinsic sense of time, to cope with unpredictable environments such as deserts, and remarkably, to generate synchronous or asynchronous breeding patterns in the tropics according to particular ecological adaptations. Maintaining seasonal animals on a constant photoperiod where the period of the light-dark (LD) cycle differs from 24-h (e.g. 23 or 25-h days) does not affect the period of the free-running circannual rhythm (bird: Gwinner, 1986; Wikelski et al., 2008 - mammal: Carmichael \& Zucker, 1986 - insect: Nisimura \& Numata, 2002), thus it is unlikely that circannual and circadian timing mechanisms are directly coupled by counting days (so called frequency demultiplication).

The second near universal timing mechanism is photoperiodic time measurement (PTM or photoperiodism). This monitors the annual cycle in daylength, and drives changes in physiology appropriate to the season. Long photoperiods ( $>12 \mathrm{~h}$ light/d) activate a summer phenotype and short photoperiods the winter state, with important species-differences in the critical daylength for these responses. This allows animals to vary the breeding season, moult and other characteristics related to latitude of origin. A change in photoperiod can activate or inhibit a seasonal response as a rapid inductive effect commencing within days (Hazlerigg et al., 2004; Nakao et al., 2008), and/or alter the long-term phasing of the endogenous circannual rhythm generators to achieve synchrony with the environment (Woodfill et al., 1994).

In mammals, the mechanism by which photoperiod is decoded is very well characterised (Goldman, 2001; Hazlerigg et al., 2001). This involves the relay of photoperiodic information from the retina to the suprachiasmatic nucleus (SCN) of the rostral hypothalamus. This bilateral tissue acts as the central circadian pacemaker generating a photoperiod-specific signal that governs the 24-h rhythmic pattern of melatonin production by the pineal gland. Melatonin is secreted only at night, and the duration of peak production reflects nightlength and thus daylength. The circulating melatonin signal is then interpreted in melatonin target tissues in the brain and pituitary gland that drive seasonal responses. The pars tuberalis (PT) of the pituitary gland is the best characterised melatonin target tissue (Hazlerigg et al., 2001; Hazlerigg \& Loudon, 2008). It is thought to decode changes in melatonin peak duration through changes in the relative phase of rhythmic Per and Cry clock gene expression (Lincoln et al., 2002; 2006b) and/or changes in amplitude of Per gene expression in the PT (Wagner et $\mathrm{al}_{+}, 2008$ ). Unlike the system generating circannual rhythms, PTM is totally dependant on the endogenous circadian system. This is because circadian clock genes control both the pacemaker function of the SCN that shapes the melatonin rhythm, and the decoding mechanisms in the PT that read the melatonin signal (Lincoln, 2006b).

The action of these two basic seasonal timing processes (circannual and PTM) can be dissociated using a constant long photoperiod protocol, as illustrated for sheep (Lincoln et al., 2005). Under the constant photoperiod, the circadian-based melatonin system remains locked to the ambient 24-h photoperiod cycle, while the circannual rhythm generator continues inexorably driving seasonal cycles in physiology (e.g. prolactin secretion). This provides an explanation for the so called 'photorefractory' response (Lincoln et al., 2005). The timing systems can also be dissociated in mammals by pinealectomy (PINX) or pineal denervation by superior cervical ganglionectomy (SCGX), which removes the melatonin signal and blocks photoperiod responsiveness (Woodfill et al., 1993; Lincoln et al., 1989). Such animals continue to express long-term reproductive rhythms albeit more variable than in intact animals. In hibernating ground squirrels, the circannual regulation is so dominant that PINX has only a marginal effect on the timing of seasonal thythms in body weight and reproduction (Hiebert et al., 2000). 


\section{Circannual rhythms throughout life}

The long-term study of hibernating chipmunkś, Tamias sibiricus, by Kondo and colleagues (Kondo et al., 2006) provides the most striking example of biology controlled as an endogenous circannual rhythm. These squirrels were maintained indoors in a simulated winter-like environment of constant dim light and cold temperature, with no daily LD cycle, for up to 11 years (Figure 2). This covered the full lifespan of the animals. Under these static conditions individual animals hibernated periodically expressing phases of hypothermia - each animal showing different circannual timing. The mean circannual tau for the cycle was 10.5 months. This period was significantly shorter than 12 months, thus squirrels must generate a phase-delay in the endogenous rhythm of 1.5 months, using the PTM response, to become stably entrained outdoors.

a) Hypothermia cycles

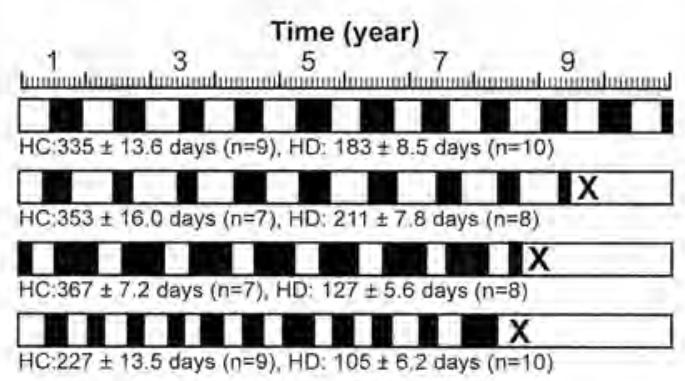

\section{b) Circannual period}

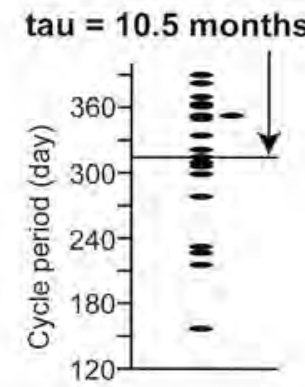

c) Liver hibernating protein cycles

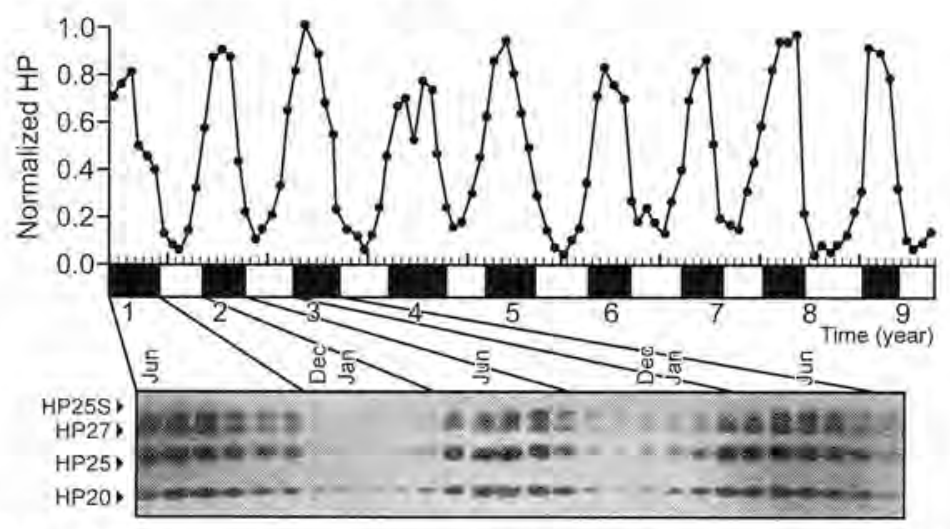

Fig. 2. Kondo's chipmunks. a) Circannual body temperature cycles in individual chipmunks (hibernating squirrels, Tamias sibiricus) housed indoors under constant cool temperature $\left(4^{\circ} \mathrm{C}\right)$ and dim light for up to 11 years. The filled bars represent the periods of hypothermia associated with hibernation; $\mathrm{HC}$, hibernation cycle (time from onset to next onset of hibernation; $H D$, hibernation duration; values mean $\pm \mathrm{SEM}: X$ animal died). b) Mean period (circannual tau) for the temperature/hibernation rhythm for 16 individual chipmunks under constant conditions (mode: 10.5 months), c) Circannual cycles in the blood concentration of specific liver proteins (called hibernation proteins, HP) in one representative chipmunk related to the temperature/hibernation rhythm (periodic filled bar) and western blots of the concentration of the 3 different HP proteins that form a complex in the blood. The HP 27 protein is shown to dissociate at the choroid plexus entering the CSF, and affects the cold temperature resistance of brain tissue. (Adapted from Kondo et al., 2006). 
Closely correlated with the hibernation rhythm were long-term cyclical changes in the blood concentrations of 3 liver proteins (so-called hibernating proteins, HP20, 25, 27) that form complexes in circulating blood. These were shown to dissociate at the level of the brain choroid plexus - with one protein entering the CNS and affecting the low-temperature tolerance of the brain (Kondo et al., 2006). There was no evidence of a progressive decline in the amplitude of the endogenous rhythm through the life history, which is a feature seen in many free-running circannual rhythms (Lincoln et al., 2006).

This remarkable persistence of circannual rhythmicity has also been documented in a passerine bird species, the stonechat Saxicola torquata, in a classical study (Gwinner, 2003). A single male bird was kept in the laboratory under an equatorial LD 12:12 lighting regimen for more than 10 years. Testis volume was measured at regular intervals through a minor incision in the abdomen, and the progression of the annual feather moult was scored. The animal expressed a gonadal cycle every 10 months with an associated post-nuptial moult throughout its entire life in captivity, registering 12 complete cycles in 10 years. There was a small change in the relative phasing of the gonadal and pelage rhythms, but they remained closely coupled throughout the life cycle. Parallel studies in other passerine bird species demonstrated that birds hand-reared in captivity, with no contact with their parents and living permanently under constant photoperiod, may express species-specific circannual rhythms in reproduction, moult, body weight and migratory restlessness, thus providing clear evidence for genetic control to a cyclical circannual programme (Gwinner, 1986).

Not all species express 'short-period' circannual rhythms: the great knot, Calidris tenuirostris, a long-distance migratory wader, expresses a free-running rhythm $>12$ months in body mass, moult and feather development under constant LD 12:12 (Piersma et al., 2008). In this case, the body mass and feather growth rhythms in part dissociated, suggesting that they may be regulated by separate oscillatory mechanisms. One specimen of the related red knot, Calidris canutus, kept indoors as a pet for 20 years replaced its feathers and changed behaviour circannually throughout life.

\section{Cyclical life histories}

The conventional view of the life history in any vertebrate is of a smooth progression from the foetus - to the juvenile - to the adult, and to senescence of old age. In this life history pattern there is a single juvenile to adult transition - we call this the generic model (Figure 3, panel A). It represents the sequence of events in short-lived species. The alternative is a cyclical model that is potentially more realistic for long-lived species (Figure 3, panel B). In this ontogenetic programme, repeated transitions between active and quiescent occur during adult life, and each represents a circannual cycle. In species adapted to cold and temperate climates, including the chipmunk and migratory birds illustrated above, the cyclic transitions of adulthood are predictably synchronised to the seasons of food plenty and scarcity - with an obvious selective advantage driving the evolution of the circannual clockwork. For species living nearer the equator where conditions are less predictable, expressing a cyclic biology can be equally advantageous, because it can increase an individual's reproductive success. This may involve focusing reproductive effort or avoiding predation, as described for seabird species living near the Equator (Ashmole \& Ashmole, 1967; Harris, 1970).

The life cycle pattern in male elephants provides an example of a long-lived, tropical species expressing delayed endogenous circannual rhythmicity and asynchrony (Figure 3C). In both African (Loxodonta) and Indian (Elephas) elephants, males characteristically express an annual musth cycle regulated by major seasonal swings in testosterone secretion (Cooper et 
al., 1990; Lincoln \& Ratnasooriya, 1996). Elephants reach puberty at 10-15 years of age when still physically immature, and overt behavioural cyclicity only develops in the second half of the life-span from 30-years onwards - by which time the bulls have grown markedly in body size and become socially dominant. The annual patterns of musth behaviour shown by the large bull elephants in the Amboseli National Park in Kenya, close to the Equator, have been recorded over many years (Poole \& Moss, 1981; Poole, 1987). These studies demonstrate that mature males have a 2-3 month musth season every year, but each individual develops its own preferred season. This 'personal' timing can be maintained over many years in the mature animals, but can be adjusted by social cues (e.g. death of a dominant male, Poole, 1987). The elephant provides an example of asynchrous cyclicity, similar to that described in tropical axis deer (Loudon \& Curlewis, 1988; Lincoln et al., 1994) and fruit bats (O'Brien, 1993; Heideman \& Bronson, 1994), although in these smaller species the endogenous cyclicity starts early in the life cycle. One ecological explanation for this phenomenon is that males avoid competition by rutting asynchronously, but as we can now understand, mechanistically they utilise an endogenous circannual clock.

a) Generic Model (Short-lived species)

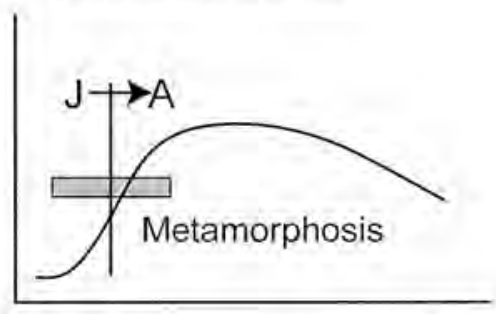

b) Cyclical Model (Seasonal species)

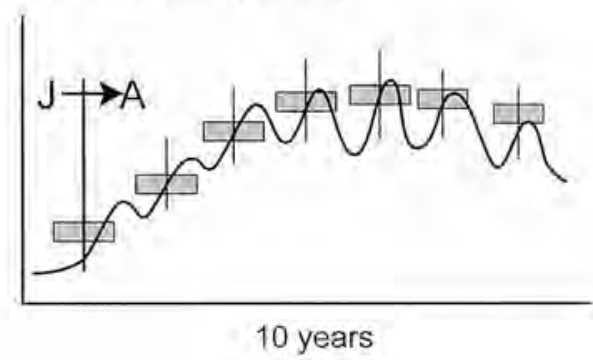

c) Delayed Cyclical Model (Elephant)

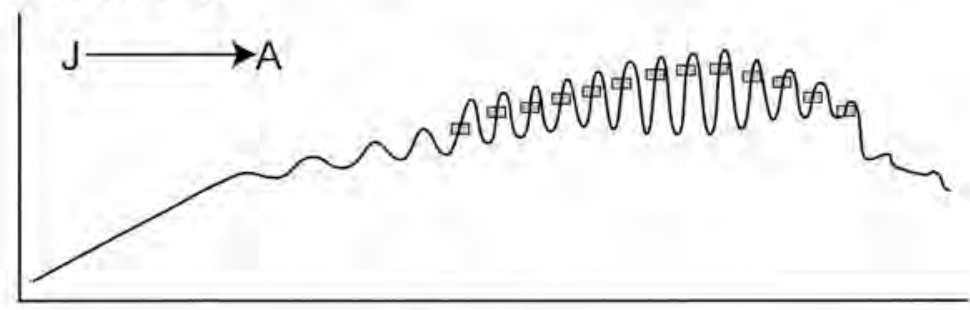

50 years

Fig. 3. Vertebrate life-history models illustrating changes in body weight or testis size. a) Generic model depicts a smooth change across the life-history with a single juvenile-adult (I-A) transition (or metamorphosis). This represents a short-lived species, b) Cyclical model with a juvenile-adult $(\mathrm{J}-\mathrm{A})$ transition followed by a series of repeated transitions throughout the life-history each representing an endogenous circannual cycle - circannual cycles are an integral part of the life-history programme. This represents a wide spectrum of seasonal species and is regarded as the ancestral pattern for vertebrates, c) Delayed cyclical model where the animal gradually matures and the circannual cyclicity in gonadal activity and sexual behaviour begins in the second half of the life history. This represents the pattern seen in male African (Loxodonta) and Indian (Elephas) elephants. 
The cyclic life-history programme accurately describes a wide spectrum of seasonal species (Figure 3). Because ancestral vertebrates were cold-blooded and most vulnerable to the adverse effects of a seasonal environment, it is logical to expect that endogenous circannual clocks evolved early in vertebrate evolution. This is consistent with the occurrence of circannual rhythmicity in fish (e.g. catfish, Sundararja et al., 1982; trout, Dunstan \& Bromage, 1988; Randall et al., 1998; stickleback, Bornestaf \& Borg, 2000 ) and reptiles (e.g. lizard species, Fisher, 1970; Cuellar \& Cuellar, 1977; Bertolucci et al., 1999). Moreover, long-lived insects and other invertebrates express circannual rhythms (Miyazaki et a., 2005) - thus circannual timing is likely to be part of ancestral life-history programmes.

\section{Circannual rhythm generators}

Ebo Gwinner states in his review of circannual rhythms (Gwinner 1986, p97) the most formidable physiological problem in circannual rhythm research arises from the extremely long duration of the process involved. Some of the changes that occur within or between the various fractions of a circannual cycle have time constants that are way beyond the range of time constants known for any neuroendocrine feedback loop and are in many respects reminiscent of developmental processes occurring during ontogeny, e.g. sexual maturation'.

This fits with the concept of the cyclical life history model and supports our new working hypothesis - the histogenesis hypothesis (Figure 4). The hypothesis proposes that circannual timing utilizes mechanisms that are an integral part of the ontogenetic life history programme where the intrinsic rhythms depend on cyclical tissue regeneration. Rhythmicity is thought to occur in multiple sites in the brain, pituitary gland and peripheral tissues where populations of progenitor cells/adult stem cells synchronously divide to initiate a new circannual cycle; this is repeated periodically during adulthood. The progeny cells proliferate, migrate and differentiate, similar to the events occurring during embryonic development, providing new tissue in the adult that drives a particular physiological transition. We envisage that some form of feedback signal from the newly differentiated cells acts to terminate the episode of progenitor cell proliferation - thus timing the circannual cycle. The trigger for the next cycle may depend on apoptosis, or some other form of regulated decline in cell function, as part of the timing mechanism.

The very long time constants of the circannual rhythm are presumed to result from the protracted nature of the differentiation process that produce new cell lineages that ultimately take control of a physiological system for many months, combined with the long intrinsic lifespan of these regenerated cells. The novel feature of this hypothesis is not in the idea of regeneration per se, since this is a feature in all tissues in the adult, but is in its synchronous nature, and in its hierarchical control co-ordinated by the brain and pituitary (see below). We propose that there must be mechanisms that govern each step of the cycle of regeneration in a specific tissue. Since 10-monthly circannual rhythms are often reported, this period will be the summation of a series of stages each lasting a few months. The presumption is that a stage is controlled by a set of genes (governing growth factors, neurogenic compounds, etc.) generating the progression of a circannual cycle. This concept of a "sequence of stages" based on tissue regeneration is fundamentally different from that originally proposed by Mrosovsky (Mrosovsky, 1970), where the proposed "stages" were physiological systems, and the cycle was the product of sequentially switching from one physiological state to the next (e.g. growth - reproduction - moult - hibernation). This later model is untenable because circannual thythms persist after ablating specific physiological systems (Lincoln et al., 2006) and circannual rhythms can dissociate (Gwinner, 1986; Martinet et al., 1992; Piersma et al., 2008). 

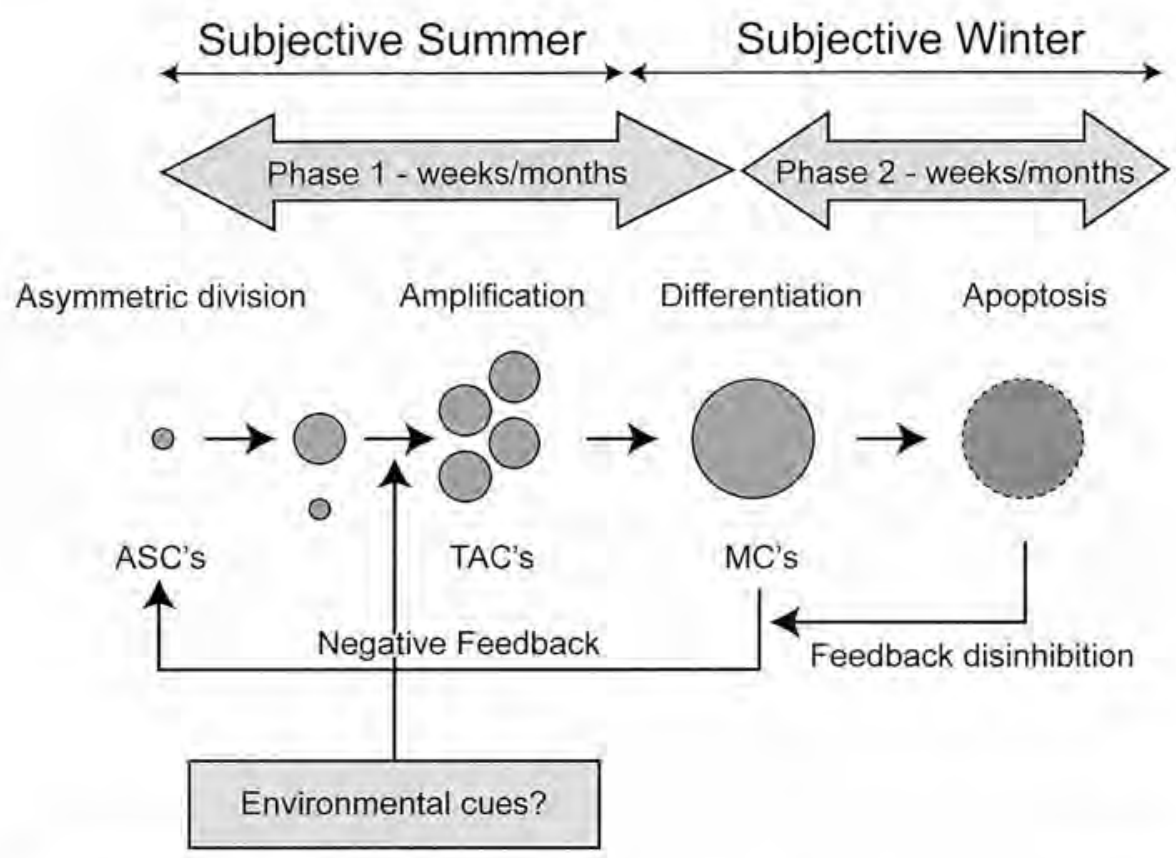

Fig. 4. Working hypothesis for the generation of circannual rhythms by histogenesis. During Phase 1 (subjective summer), adult stem cells (ASCs) divide asymmetrically within a stem cell niche producing transient amplifying cells (TACs) that move out and divide multiple times, before differentiating into mature cells (MCs) that express specific marker genes. We propose that these mature cells produce negative feedback signals that block further ASC and TAC division. This initiates Phase 2 (subjective winter) during which negative inhibition persists until apoptosis of MCs or some other form of spontaneous tissue change causes feedback disinhibition to trigger the next circannual cycle. Environmental cues notably photoperiod, but other factors as well, are thought to be relayed to the sites of tissue regeneration and alter timing. This causes a change in phase (advance or delay according to the stage of the cycle) and permits entrainment to a seasonal environment,

We propose that photoperiod and other environmental cues act at specific stages of the regenerative cycle to alter the period of the circannual rhythm to permit entrainment. This could be during the proliferative phase of the endogenous cycle where the extrinsic signal acts to suppress or prolong the propagation of new cells, thus causing a phase-advance or -delay in the intrinsic cycle generator (Figure 4). This is analogous to the manner daily light signals entrain the circadian clock by affecting the rhythmic expression of specific clock genes (Reppert \& Weaver, 2002). A phase-response curve for the effect of long photoperiod has been described in the trout (Dunstan \& Bromage, 1988), European hamster (Monecke et al., 2009), and in detail in the carpet beetle, Anthrenus (Miyazaki et al., 2007). The circannual clock behaves like a readily entrainable oscillator (Miyazaki et al., 2005; Lincoln et al., 2006). While circannual and circadian rhythms are undoubtedly generated by different genetic mechanisms, their formal entrainment properties are remarkably similar. 


\section{Circannual rhythm generators}

Histogenesis in the pituitary gland

The pars tuberalis (PT) of the pituitary gland is a very well characterised melatonin target tissue that may act as a specialised circannual timer (Hazlerigg et al., 2001; Lincoln, 2002; Lincoln et al., 2003a \& b) (Figure 5). The PT expresses a high density of melatonin $\mathrm{mt}$ receptors in the adult in a wide range of seasonal mammals and birds. The tissue is strategically located at the gateway between the brain and pituitary gland, and potentially regulates long-term cycles in several major physiological systems. The main secretory cell-type is the PT thyrotroph - distinct from the thyrotrophs of the pituitary pars distalis (PD) that secrete TSH to control the peripheral thyroid axis (Bockmann et al., 1997; Wittkowski et al., 1999).

The PT cells, by contrast, secrete TSH that acts locally in the mediobasal hypothalamus to regulate thyroid hormone dependant mechanisms and thus drive seasonal biology (Nakao et al., 2008; Hanon et al., 2008; Ono et al., 2009). This involves TSH activation of deiodinase type-2 $\left(\mathrm{DIO}_{2}\right)$ in the adjacent tanycytes that line the base of the third ventricle $(3 \mathrm{~V})$, catalysing the conversion of thyroxin (T4) to its biologically active form tri-iodothyronine (T3). It is the local increase in T3 that activates a cascade of neuroendocrine responses induced by long photoperiod to produce a summer reproductive phenotype (Hazlerigg \& Loudon, 2008). The PT cells also secrete other factors that act in a more predictable retrograde manner in the pituitary gland itself. This includes neurokinins that modulate prolactin production by lactotrophs to regulate the seasonal reproductive changes and the pelage moult cycle (Dupre et al., 2010).

Strong evidence that the pituitary gland and particularly the PT acts as a circannual rhythm generator comes from studies using hypothalamo-pituitary disconnected (HPD) Soay sheep (Lincoln et al., 2006). The HPD operation permanently destroys the arcuate nucleus and median eminence and consequently the PT control of the mediobasal hypothalamus, but spares the PT regulation of the lactotrophs (Figure 5). HPD sheep are sexually inactive indicative of the loss of hypothalamic regulation, but continue to express normal cyclical changes in prolactin secretion and the associated moult. Long photoperiod activates, and short photoperiod suppresses, prolactin release (Lincoln \& Clarke, 1994; Lincoln, 2002), and exposure to constant long photoperiod produces circannual rhythms in prolactin that persist for at least 4 cycles (Lincoln et al., 2006). Circannual tau is close to 10 months in the HPD sheep. The generation of the circannual rhythm has been mathematically modelled based on the interaction between the melatonin-responsive thyrotroph cells in the PT and the lactotrophs in the PD, and predicts very long feedback delays in the clockwork mechanism (MacGregor \& Lincoln, 2008).

The PT may act as a specialised circannual timer because it contains undifferentiated/uncommitted cells that can activate a protracted cycle of cell differentiation and decline (Wittkowski et al., 1999; Hazlerigg, 2001). We have just begun to measure changes in the rate of cell proliferation in the PT and the MBH in Soay sheep using bromodeoxyuridine (BrDU) to label dividing cells (Figure 6). Labelled cell nuclei were counted at 24-hours after BrDU treatment. Proliferation rates in the PT and $\mathrm{MBH}$ were maximal at 4 weeks into long photoperiod and decreased spontaneously by 20 weeks long photoperiod associated with the progression of the circannual cycle (photorefractory state). Following a switch in photoperiod, lowest proliferation was at 4 weeks into short photoperiod. This is the beginning of an expansive study to identify the phenotype of the dividing cells and trace their fate after differentiation.

\section{Neurogenesis in the brain}

There are multiple sites of neurogenesis in the adult brain that may act as tissue timers and contribute to long-term timing. Of particular interest in relation to thyroid hormone control 

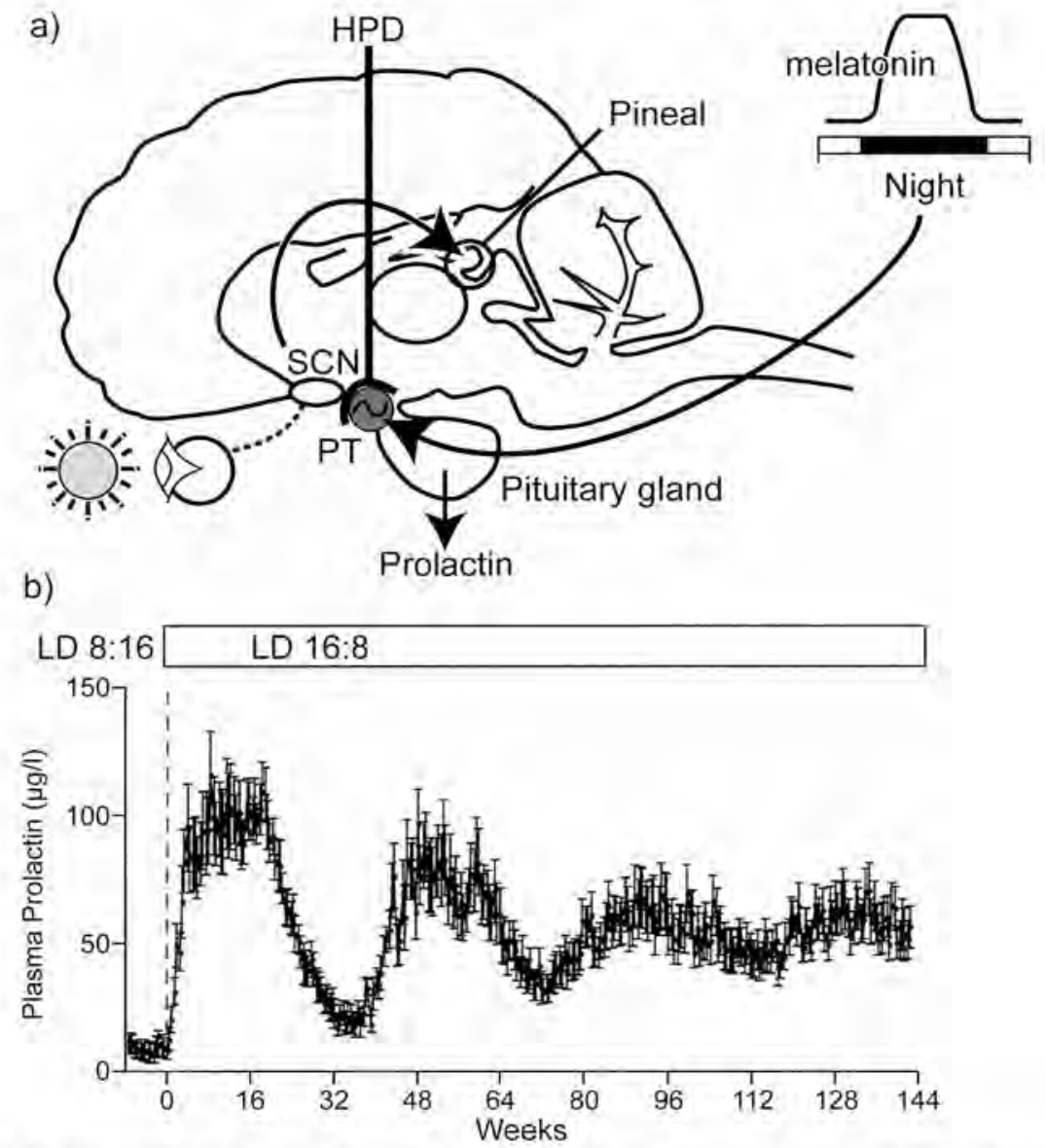

Fig. 5. Hypothalamo-pituitary disconnected (HPD) Soay sheep under constant photoperiod. a) Diagram of the sheep brain illustrating the relay by which light information is transmitted from the retina to the suprachiasmatic nucleus ( $\mathrm{SCN}$, central circadian pacemaker) and to the pineal gland that produces a nocturnal melatonin signal that reflects the photoperiod. The melatonin signal acting via the blood is then decoded in the pars tuberalis (PT) of the pituitary gland to affect prolactin secretion from the pituitary lactotrophs. Note, the HPD operation permanently destroys the median eminence and arcuate nucleus isolating the pituitary from direct regulation by the hypothalamus (see HPD, curve line) but maintains the signalling by melatonin. b) Long-term prolactin profiles in HPD Soay transferred from short photoperiod (LD 8:16) to long photoperiod (LD 16:8) and kept under long photoperiod for 144 weeks. A circannual prolactin rhythm was evident in all HPD sheep that persisted for at least 4 cycles becoming asynchronous, and dampening in amplitude with time. The mean circannual tau was 10.2 months. Values are mean \pm SEM, $n=10$. (Adapted from Lincoln et àl., 2006).

by the PT, is the subventricular zone (SZH) surrounding the base of the $3 \mathrm{~V}$ in the mediobasal hypothalamus. The tanycytes in this region appear to be progenitor cells, whose progeny can migrate into target regions including the lateral hypothalamus and arcuate nuclei to adopt hypothalamic neuronal fates (Xu et al., 2005; Hajihosseini et al., 2008). Changing neurogenesis in the SZH may thus alter the hypothalamic functional set-points, and drive long-term cycles 
a)

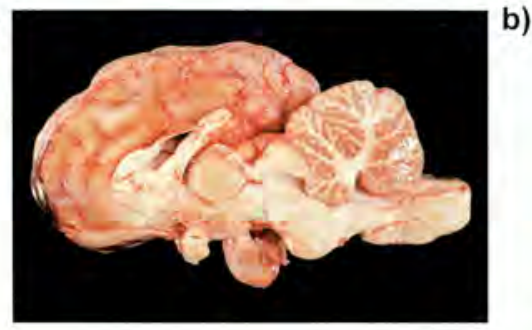

BrDU staining

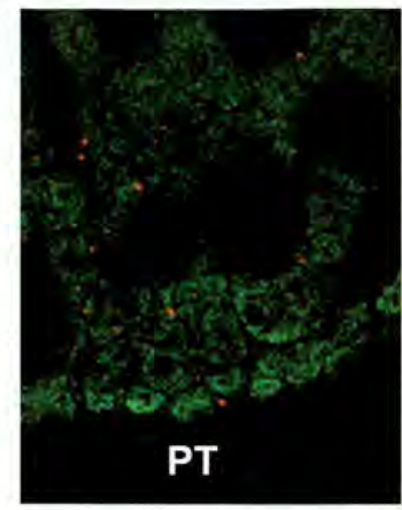

Fig. 6. Photoperiod-induced cell proliferation in the sheep PT and mediobasal hypothalamus, a) Sheep brain cut along the mid-line showing the site of the histological section. b) Coronal section of the sheep pituitary pars tuberalis (PT) and median eminence (ME), immuno-stained to reveal bromo-deoxyuridine (BrDU) labelled cells, indicative of cells that divided within the last $24 \mathrm{~h}$. Left panel, PT BrDU positive cells labelled in red; right panel, PT and ME BrDU positive cells labelled in brown. Images from Cathy Wyse.

in physiology and behaviour. This concept is supported by studies of changes in body weight and energy metabolism in laboratory mice induced by the central administration of cilary neurotrophic factor (CNTF) (Kokoeva et al., 2005). This treatment caused cell proliferation in the $\mathrm{SZH}$, migration of progeny cells to the appetite regulatory centres in the paraventricular hypothalamus and differentiation into neurones expressing appetite regulatory peptides. There was a corresponding change in food intake and body weight that lasted several months after the end of treatment. We have recently demonstrated that the cntf gene is expressed in the PT and CNTF receptor is expressed in the adjacent mediobasal hypothalamus in our Soay sheep model, consistent with a role in regulating seasonal rhythms (E. Hanon unpublished data).

Cell proliferation also occurs in the adult brain in the subventricular zone of the lateral ventricle (SVZ), producing a rostral stream of progenitor cells that differentiate in the olfactory bulb, and in the subgranular zone (SGZ) of the dentate gyrus of the hippocampus where the new cells become granular cell neurones contributing to learning and spatial memory. Seasonal changes in hippocampal neurogenesis have been well studied in birds related to song control in the breeding season and food caching in winter (Nottebohm, 1989; Barnea \& Nottebohm, 1994) and related to repeated long distance migration (Pravosudov et al., 2006). Long-term changes also occur in mammals related to season, photoperiod and/or sex hormonal status (Huang et al., 1998; Galea \& McEwen, 1999; Lavenex et al., 2000; Pyter et al., 2005; Xu. et al., 2005). In adult golden hamsters, the number of BrDU positive cells in the dentate gyrus and subependymal zone doubled in animals exposed to short photoperiod (Huang et al., 1998).

\section{Circannual pacemaker shop}

The histogenesis hypothesis extends to include regenerative mechanisms in the brain, pituitary and in a range of other peripheral body organs in the control of circannual rhythms. The concept of a circannual pacemaker shop is summarised in Figure 7. In this model, all tissues have a major degree of autonomy in their regeneration and thus can contribute to long-term timing of physiological cycles in the adult. The key feature in animals with a cyclical life history is the 
degree to which proliferation is synchronised within an organ or physiological system, with the timing entrainable by environmental cues. The evidence for long-term cycling in a peripheral organ is illustrated in chipmunks expressing circannual rhythms in liver proteins related to the control of hibernation (Figure 5). While the cyclicity is intrinsic to different tissues, it may require co-ordination by the PT, mediobasal hypothalamus and possibly elsewhere in the brain, to govern the functional state of the whole body, which requires appropriate phasing of the different circannual pacemakers (Figure 7). This again has parallels with the co-ordination of the circadian system by the $\mathrm{SCN}$. The circannual clockwork is presumed to have much greater inertia because it is based on histogenesis; hence migratory animals (or globe-trotting humans) will not suffer seasonal jet lag!

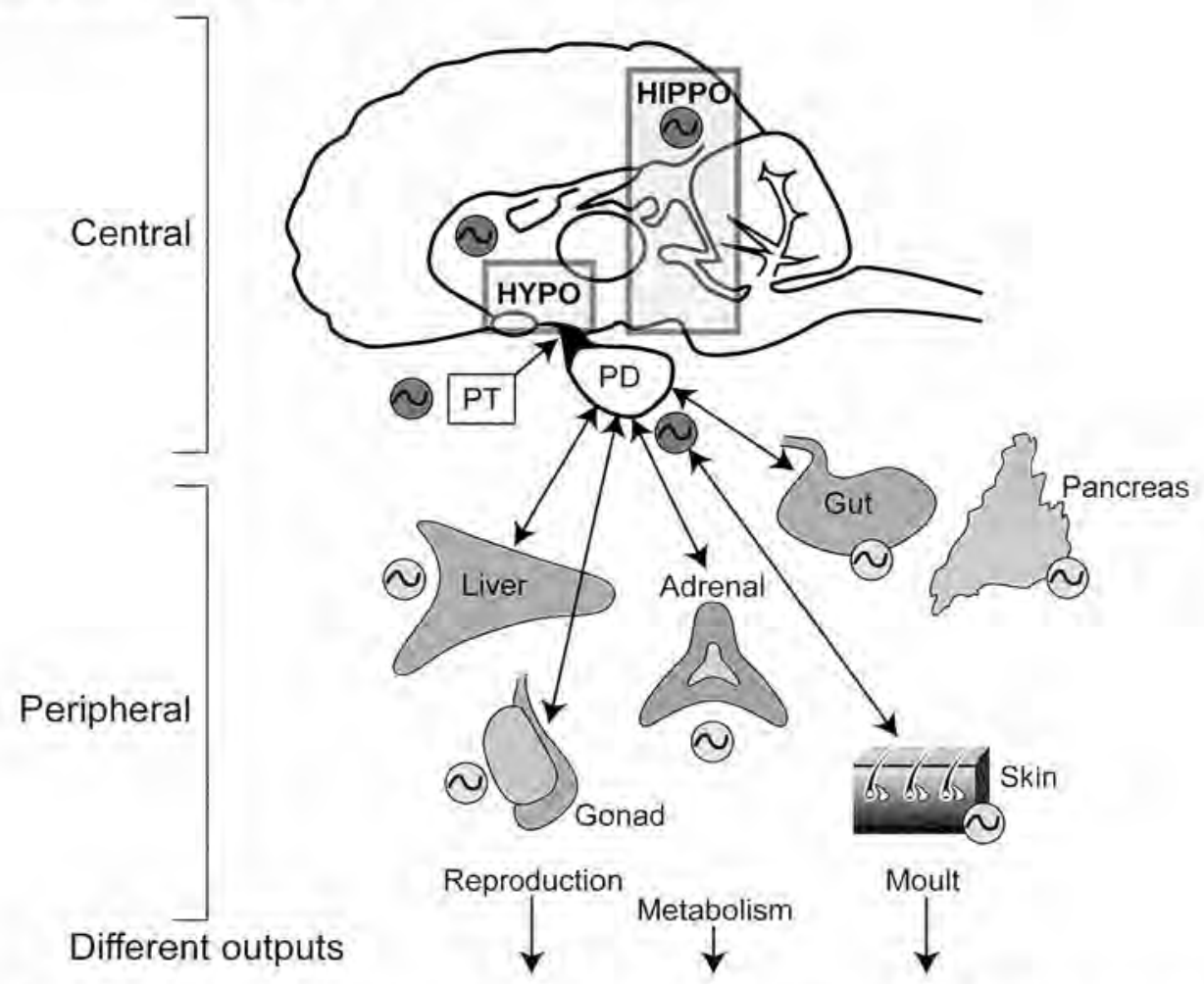

Fig. 7. The Circannual System. The current concept is that there are multiple sites in the brain, pituitary and peripheral organs where cyclical histogenesis contributes to the circannual rhythmicity. Each physiological system (regulating reproduction, metabolism, moult etc) is thought to have its own circannual timer with brain/pituitary sites potentially providing for integration of the multiple systems, and allowing entrainment to environmental cues. Parallels are drawn with the circadian system where the SCN acts as a central pacemaker for peripheral clocks. Autonomy of circannual timers allows for major species differences in the timing of the various physiological rhythms.

The hair follicle provides a model of a tissue-based clock (Schneider et al., 2009). This structure is a mini-organ capable of growing a complete hair over a period of many weeks modulated by hormones and other signals, and the genes controlling the initiation, growth, morphological form, maturation and rest phases are very well characterised based on mutagenesis analysis in mice. Nestin-expressing adult cells localised in the bulb region of the resting hair follicle ap- 
pear to initiate the next growth cycle, but the intrinsic clock/timer is still a mystery (Schneider et al., 2009). In seasonal animals, the hair follicles alternate between growing short, fine hairs in summer and long, thicker insulating hairs in winter, and the cycle is regulated in part by seasonal changes in prolactin secretion (Choy et al., 1995; Lincoln et al., 2003b). Evidence that this cyclic state is also intrinsically controlled at the level of the skin is provided by a study in red deer (Cervus elaphus) in which animals in their winter coat were treated with a subcutaneous implant that infused prolactin locally into the skin over a period of 28 days (Loudon \& Jabbour, 1994). This induced the premature growth of a small patch of red summer coat, which subsequently reversed to growing a winter coat, and remained out of synchrony with the hair follicles of the rest of the body for at least 6 months, before realignment. This nicely illustrates a degree of autonomy of timing in a peripheral tissue - fitting into the concept of an integrated timing system (Figure 7).

Regulated regenerative processes are a feature of all tissues and are currently the focus of intensive research effort in liver (Forbes et al., 2002), heart (Anversa et al., 2004), pituitary (Levy 2008; Fauquier et al, 2008; Gleiberman el al., 2008), hair follicles (Schneider et al., 2009) and testis (Davidoff et al., 2004). The aim is to characterise stem cell niches, isolate stem cells and to identify the growth factors and other signals produced by the differentiation of mature cell lineages. In these model systems, synchronous regeneration (as seen in seasonal animals) can be induced by tissue ablation. Resection of a major part of the liver, for example, triggers a synchronous wave of cell division involving multiple progenitor cell types derived from the biliary tree and associated blood vascular structures of the liver. This proliferative process slows once the liver mass recovers to normal indicating the involvement of negative feedback signalling for tissue homeostasis. Similarly, treatment of rats with the toxin ethane dimethanesulphonate (EDS) specifically ablates the Leydig cells in the adult testis removing the source of testosterone, and triggers the synchronous regeneration of a new population of Leydig cells (Davidoff et al., 2004). In this case, stem cells are located in the vascular endothelial tissue of the blood vessels and migrate out into the interstitial tissue and differentiate into new Leydig cells. There is a sequential activation of cell-specific genes over a period of 28 days including the genes regulating testicular steroidogenesis (Davidoff et al., 2004). The local tissue signals that trigger the initial proliferation and later curtail the regeneration response are still to be identified.

\section{Conclusions}

We propose that cyclical histogenesis forms the basis of endogenous circannual rhythm generation as an integral part of the life history programme. This is ancestrally cyclical in vertebrates. Regenerative mechanisms persist throughout adulthood driving rhythms of growth and decline across the year. The endogenous timing is adaptive because it allows the organism to profoundly change its physiology and phenotype over long time-scales of many months to anticipate environmental change and thus maximise survival and reproductive success. We present preliminary evidence that cyclical histogenesis occurs in specific sites in the pituitary gland, brain and peripheral tissues that potentially govern circannual rhythms in reproduction, moult and other characteristics. It is likely that each physiological system has its own circannual timer mechanism, integrated centrally to produce the circannual timing system that differs between species. Parallels are drawn with the control of the circadian system where the SCN provides a central pacemaker. At present, the pituitary PT is the best candidate for a central circannual pacemaker. Our current aim is to manipulate cell proliferation mechanisms in the PT and hypothalamus in our Soay sheep model to investigate effects on circannual rhythms, and to characterise the adult stem cell niches in these circannual timing tissues. 


\section{Acknowledgements}

Our special thanks go to Joan Docherty, Marjorie Thomson, and the staff of the Marshall Building for their dedicated help in running the large animal facility, to Cathy Wyse (University of Aberdeen) and Elodie Hanon (University of Edinburgh) for use of histology images and related data, to Ronnie Grant (University of Edinburgh) for the graphics and to Barbara Helm (University of Konstanz, Germany) for her constructive comments on the manuscript. The work was supported by grants from the MRC and BBSRC, UK

\section{References}

Anversa P, Kajstura J, Leri A 2004 Circulating progenitor cells: search for an identity. Circulation 110 3158-3160.

Ashmole NP, Ashmole MJ 1967 Comparative feeding ecology of seabirds of a tropicak oceanic island. Peabody Mus Nat Hist, Bull 24.

Barnea A, Nottebohm F 1994 Seasonal recruitment of hippocampal neurons in adult free-ranging blackcapped chickadees. Proc Natl Acad Sci U S A. 91 11217-11221.

Bertolucci C, Leorati M, Innocenti A, Foa A 1999 Circannual variations of lizard circadian activity rhythms in constant darkness. Behav Ecol Sociobiol 46 200-209.

Bockmann J, Böckers TM, Winter C, Wittkowski W, Winterhoff H, Deufel T, Kreutz MR 1997 Thyrotropin expression in hypophyseal pars tuberalis-specific cells is $3,5,3^{\prime}$-triiodothyronine, thyrotropin-releasing hormone, and pit-1 independent. Endocrinology 138 1019-1928.

Bornestaf C, Borg B 2000 Endogenous breeding cycles in male threespine sticklebacks, Crasterosteus aculeatus. Behaviour 137 921-932.

Carmichael MS, Zucker I 1986 Circannual rhythms of ground squirrels: a test of the frequency demultiplication hypothesis. I Biol Rhythms 1 277-284.

Choy VJ, Nixon AJ, Pearson AJ 1995 Distribution of prolactin receptor immunoreactivity in ovine skin and changes during the wool follicle growth cycle. I Endocrinol 155 265-275.

Concannon P, Roberts P, Baldwin B, Tennant B 1997 Long-term entrainment of circannual reproductive and metabolic cycles by Northern and Southern Hemisphere photoperiods in woodchucks (Marmota monax). Biol Reprod 57 1008-1015.

Cooper KA Harder JD, Clawson DH, Frederick DL Lodge GA Peachey HC Spellmire TJ Winstel DP 1990 Serum testosterone and musth in captive African and Asian elephants. Zoo Biol 9 297-306.

Cuellar HS, Cuellar O 1977 Evidence for endogenous rhythmicity in the reproductive cycle of the parthenogenic lizard Cnemidophorus uniparens. Copeia 19 554-557.

Davidoff MS, Middendorff R, Enikolopov G, Riethmacher D, Holstein AF, Müller D 2004 Progenitor cells of the testosterone-producing Leydig cells revealed. / Cell Biol 167 935-944.

Ducker MJ, Bowman JC, Temple A 1973 The effect of constant photoperiod on the expression of oestrus in the ewe. I Reprod Fertil Suppl 19 143-150.

Dunstan J, Bromage N 1988 The entrainment and gating of the endogenous circannual rhythms of reproduction in the female rainbow trout (Salmo gairdneri). I Comp Physiol A 164 259-268.

Dupré SM, Miedzinska K, Duval CV, Yu L, Goodman RL, Lincoln GA, Davis JR, McNeilly AS, Burt DD, Loudon AS 2010 Identification of Eya3 and TAC1 as long-day signals in the sheep pituitary. Curr Biol 20 829-35.

Fauquier T, Rizzoti K, Dattani M, Lovell-Badge R, Robinson IC 2008 SOX2-expressing progenitor cells generate all of the major cell types in the adult mouse pituitary gland. Proc Natl Acad Sci U S A 105 2907-2912.

Fisher K 1970 Untersuchungen zur Jahresperiodik der Fortpflanzung bei mannlichen Ruineneidechsen (Lacerta sicula campestris Betta). III. Spontanes Einsetzen und Ausklingen der Gonadenaktivitat; ein Beitrag zur Frage der circannualen Periodik. Z Vergl Physiol 66 273-293.

Forbes S, Vig P, Poulsom R, Thomas H, Alison M. 2002 Hepatic stem cells. / Pathol 197 510-518. Review.

Galea LA, McEwen BS 1999 Sex and seasonal differences in the rate of cell proliferation in the dentate gyrus of adult wild meadow voles. Neuroscience 89 955-964.

Gleiberman AS, Michurina T, Encinas JM, Roig JL, Krasnov P, Balordi F, Fishell G, Rosenfeld MG, Enikolopov G 2008 Genetic approaches identify adult pituitary stem cells. Proc Natl Acad Sci U S A 105 6332-6337.

Goldman BD 2001 Mammalian photoperiodic system: formal properties and neuroendocrine mechanisms of photoperiodic time measurement. I Biol Rhythms 16 283-301.

Gómez-Brunet A, Santiago-Moreno J, del Campo A, Malpaux B, Chemineau P, Tortonese DJ, Gonzalez-Bulnes A, López-Sebastián A 2008 Endogenous circannual cycles of ovarian activity and changes in prolactin and melatonin secretion in wild and domestic female sheep maintained under a long-day photoperiod. Biol Reprod 78 552-62.

Goss RJ 1977 Photoperiodic control of antler cycles in deer. IV Effects of constant light:dark ratios on circannual rhythms. J Exp Zool 201 379-382.

Goss R) 1984 Photoperioduc control of antler cycles in deer. VI Circannual rhythms on altered day lengths. I Expl Zool 230 265-272.

Gwinner E 1986 Circannual Rhythms: Endogenous Annual 
Clocks in the Organization of Seasonal Processes pp 1-156. Berlin: Springer-Verlag.

Gwinner E 1996 Circadian and circannual programmes in avian migration, / Exp Biol 199 39-48.

Gwinner E 2003 Circannual rhythms in birds, Curr Opin Neurobiol 13 770-778. Review.

Hajihosseini MK, De Langhe S, Lana-Elola E, Morrison H, Sparshott N, Kelly R, Sharpe J, Rice D, Bellusci S 2008 Localization and fate of Fgf10-expressing cells in the adult mouse brain implicate Fgf 10 in control of neurogenesis. Mol Cell Neurosci 37 857-868.

Hanon EA, Lincoln GA, Fustin JM, Dardente $H$, MassonPévet M, Morgan PJ, Hazlerigg DG 2008 Ancestral TSH mechanism signals summer in a photoperiodic mammal. Curr Biol 18 1147-1152.

Harris MP 1970 Breeding ecology of the swallow-tailed gull, Creagrus furcatus. Auk 87 215-243.

Hazlerigg DG, Andersson H, Johnston ID, Lincoln G 2004 Molecular characterization of the long-day response in the Soay sheep, a seasonal mammal. Curr Biol 14 334-339.

Hazlerigg D, Loudon A 2008 New insights into ancient seasonal life timers. Curr Biol 18 R795-R804. Review.

Hazlerigg DG, Morgan PJ, Messager S 2001 Decoding photoperiodic time and melatonin in mammals: what can we learn from the pars tuberalis? I Biol Rhythms 200116 326-335. Review.

Heideman PD, Bronson FH 1994 An endogenous circannual rhythm of reproduction in a tropical bat, Anoura geoffroyi, is not entrained by photoperiod. Biol Reprod 50 607-14.

Herbert I Stracey PM Thorpe DH 1978 Recurrent breeding season in pinealectomized or optic-nerve -sectioned ferrets. J Endocrinol 78 389-397.

Hiebert SM, Thomas EM, Lee TM, Pelz KM, Yellon SM, Zucker I 2000 Photic entrainment of circannual rhythms in golden-mantled ground squirrels: role of the pineal gland. I Biol Rhyth 15 126-134.

Huang L, DeVries GJ, Bittman EL 1998 Photoperiod regulates neuronal bromodeoxyuridine labeling in the brain of a seasonally breeding mammal. / Neurobiol 36 410-420.

Karsch FJ, Robinson JE, Woodfill C], Brown MB 1989 Circannual cycles of luteinizing hormone and prolactin secretion in ewes during prolonged exposure to a fixed photoperiod: evidence for an endogenous reproductive. rhythm. Biol Reprod 41 1034-1046.

Kokoeva MV, Yin H, Flier JS 2005 Neurogenesis in the hypothalamus of adult mice: potential role in energy balance. Science 310 679-683.

Kondo N, Sekijima T, Kondo J, Takamatsu N, Tohya K, Ohtsu T 2006 Circannual control of hibernation by HP complex in the brain. Cell 125 161-172.

Lavenex P, Steele MA, Jacobs LF 2000 The seasonal pattern of cell proliferation and neuron number in the dentate gyrus of wild adult eastern grey squirrels. Eur I Neurosci 12 643-648.

Levy A 2008 Stem cells, hormones and pituitary adenomas. I Neuroendocrinol 20 139-140. Review.

Lincoln G, Messager S, Andersson H, Hazlerigg D 2002
Temporal expression of seven clock genes in the suprachiasmatic nucleus and the pars tuberalis of the sheep: evidence for an internal coincidence timer. Proc Natl Acad Sci U S A. 99 13890-13895.

Lincoln GA 2002 Neuroendocrine regulation of seasonal gonadotrophin and prolactin rhythms: lessons from the Soay ram model. Reproduction Suppl 59:131-147. Review.

Lincoln GA 2006a Melatonin entrainment of circannual rhythms. Chronobiol lnt 23 301-306.

Lincoln GA 2006b Decoding the nightly melatonin signal through circadian clockwork. Mol Cell Endocrinol 252 69-73.

Lincoln GA, Andersson H, Hazlerigg D 2003a Clock genes and the long-term regulation of prolactin secretion: evidence for a photoperiod/circannual timer in the pars tuberalis. I Neuroendocrinol 15 390-7. Review.

Lincoln GA, Andersson H, Loudon A 2003 b Clock genes in calendar cells as the basis of annual timekeeping in mammals - a unifying hypothesis. I Endocrinol 1791-13, Review.

Lincoln GA, Clarke If 1994 Photoperiodically-induced cycles in the secretion of prolactin in hypothalamopituitary disconnected rams: evidence for translation of the melatonin signal in the pituitary gland. I Neuroendocrinol 6 251-60.

Lincoln GA, Clarke II, Hut RA, Hazlerigg DG 2006 Characterizing a mammalian circannual pacemaker. Science 314 1941-1944.

Lincoln GA, Dayawansa N, Ratnasooriya WD 1994 Characteristics of the antler cycle in male axis deer (Axis axis) living in Sri Lanka close to the Equator. In Recent developments in deer biology pp 213-214 Ed: JA Milne. Moredun Research Institute, Edinburgh.

Lincoln GA, Johnston JD, Andersson H, Wagner G, Hazlerigg DG 2005 Photorefractoriness in mammals: dissociating a seasonal timer from the circadian-based photoperiod response. Endocrinology $1463782-3790$.

Lincoln GA Libre EA, Merriam GR 1989 Long-term reproductive cycles in rams after pinealectomy or superior cervical ganglionectomy. J reprod Fertil 85 687-704.

Lincoln GA, Rafnasooriya WD 1996 Testosterone secretion, musth behaviour and social dominance in captive male Asian elephants living near the equator. I Reprod Fertil 108 107-113.

Loudon ASI \& Curlewis JD 1988 Cycles in antler and testicular growth in a aseasonal tropical deer (Axis axis) . Reprod Fert 83 729-738

Loudon ASI \& Jabbour HN 1994 Seasonal rhythms in the physiology of deer: endogenous clocks and target tissues. In Recent developments in deer biology pp 197-207 Ed: JA Milne. Moredun Research Institute, Edinburgh.

Macgregor DJ, Lincoln GA 2008 A physiological model of a circannual oscillator. I Biol Rhythms 23 252-264.

Martinet L, Mondain-Monval M, Monnerie R 1992 Endogenous circannual rhythms and photorefractoriness of testis activity, moult and prolactin concentrations in mink (Mustela vison). J Reprod Fertil 95 325-38. 
Miyazaki Y, Nisimura T, Numata H 2007 Phase resetting and phase singularity of an insect circannual oscillator. I Comp Physiol A Neuroethol Sens Neural Behav Physiol 193 1169-1176.

Miyazaki Y, Nisimura T, Numata H 2009 A circadian system is involved in photoperiodic entrainment of the circannual rhythm of Anthrenus verbasci. I Insect Physiol 55 494-498.

Miyazaki Y, Nisimura T, Numata H 2005 A phase response curve for circannual rhythm in the varied carpet beetle Anthrenus verbasci. J Comp Physiol A 191 883-887. 494-498.

Monecke S, Saboureau M, Malan A, Bonn D, MassonPevet M, Pevet P 2009 Circannual phase-response curves to short and long photoperiod in the European hamster. I Biol Rhyth 24 413-426.

Mrosovsky N 1970 Mechanism of hibernation cycles in ground squirrels: circannian rhythm or sequence of stages. Pennsylvania Acad Sci 44 172-175.

Mrosovsky N 1978 Circannual cycles in hibernators pp21-65. In: Strategies in cold: natural torbidity and thermogenesis. Eds: LCH Wang, Hudson JW. Academic Press, New York.

Nakao N, Ono H, Yamamura T, Anraku T, Takagi T, Higashi K, Yasuo S, Katou Y, Kageyama S, Uno Y, Kasukawa T, ligo M, Sharp PJ, Iwasawa A, Suzuki Y, Sugano S, Niimi T, Mizutani M, Namikawa T, Ebihara S, Ueda HR, Yoshimura T 2008 Thyrotrophin in the pars tuberalis triggers photoperiodic response. Nature $452317-322$.

Nisimura I Numata H 2002 Evaluation of the frequency demultiphication hypothesis of circannual pupation rhythm in the varied carpet beetle Anthrenus verbasci (Coleoptera: Dermestidae). Biol Rhythm Res 33255 260.

Nottebohm F 1989 From bird song to neurogenesis. Sci Am 260 74-79.

O'Brien GM 1993 Seasonal reproduction in flying foxès, reviewed in the context of other tropical mammals. Reprod Fertil Dev 5499-521. Review.

Ono H, Nakao N, Yoshimura T 2009 Identification of the photoperiodic signaling pathway regulating seasonal reproduction using the functional genomics approach, Gen Comp Endocrinol 163 2-6. Review.

Pengelley ET, Asmundson SJ 1974 Circannual Rhythmicity in hibernating animals. Circannual Clocks pp 96-120 Ed ET Pengelly. San Francisco: Academic Press.

Piersma T, Brugge M, Spaans B, Battley PF 2008 Endog. enous circannual rhythmicity in body mass, molt and plumage of great knots (Calidris tenuirostris). The Auk $125140-148$.

Poole JH 1987 Rutting behavior of African elephants: the phenomina of musth. Behaviour 102 283-316.

Poole JH Moss C) 1981 Musth in the African elephant, Loxodonta Africana. Nature $292830-831$.
Pravosudov VV, Kitaysky AS, Omanska A 2006 The relationship between migratory behaviour, memory and the hippocampus: an intraspecific comparison. Proc Biol Sci 273 2641-2649.

Pyter LM, Reader BF, Nelson RI 2005 Short photoperiods impair spatial learning and alter hippocampal dendritic morphology in adult male white-footed mice (Peromyscus leucopus). J Neurosci 25 4521-4526.

Randall CF, Bromage NR, Duston J, Symes J 1998 Photoperiod-induced phase-shifts of the endogenous clock controlling reproduction in the rainbow trout: a circannual phase-response curve. I Reprod Fertil 112 399-405.

Reppert SM, Weaver DR 2002 Coordination of circadian timing in mammals. Nature 418 935-941.

Schneider MR, Schmidt-Ullrich R, Paus R 2009 The hair follicle as a dynamic miniorgan. Curr Biol 19R132-142. Review.

Sundararaj BI, Vasal S, Halberg F 1982 Circannual rhythmic ovarian recrudescence in the catfish Heteropneustes fossilis (Bloch). Adv Biosci 41 319-337.

Wagner GC, Johnston JD, Clarke IJ, Lincoln GA, Hazlerigg DG 2008 Redefining the limits of day length responsiveness in a seasonal mammal. Endocrinology 149 32-39.

Wehr TA 2001 Photoperiodism in humans and other primates: evidence and implications. I Biol Rhythms 16 348-64. Review.

Wickings EJ, Nieschlag E 1980 Seasonality in endocrine and exocrine testicular function of the adult rhesus monkey (Macaca mulatta) maintained in a controlled laboratory environment. Int / Androl 1980 3 87-104.

Wikelski M, Martin LB, Scheuerlein A, Robinson MT, Robinson ND, Helm B, Hau M, Gwinner E 2008 Avian circannual clocks: adaptive significance and possible involvement of energy turnover in their proximate control. Phil Trans Roy Soc B Biol Sci 363 411-423.

Wittkowski W, Bockmann J, Kreutz MR, Böckers TM 1999 Cell and molecular biology of the pars tuberalis of the pituitary. Int Rev Cytol 185 157-94. Review

Woodfill CJ, Wayne NL, Moenter SM, Karsch FJ 1994 Photoperiodic synchronization of a circannual reproductive rhythm in sheep: identification of season-specific time cues. Biol Reprod 50 965-976.

Xu Y, Tamamaki N, Noda T, Kimura K, Itokazu Y, Matsumoto N, Dezawa M, Ide C 2005 Neurogenesis in the ependymal layer of the adult rat 3 rd ventricle. Exp Neurol 192 251-264.

Zucker I 2001 Circannual Rhythms: mammals. In Handbook of Neurology, vol 12, Circannual Clocks pp 509-528 Eds jS Takashi, FW Turek, RY Moore. New York: Plenum Publishers. 